\title{
Fat Embolism Syndrome after Lower Extremity Fracture
}

\author{
Mustafa Burak Sayhan', Ömer Salt', Mert Özcan², Volkan Mumcu', Burcu Filizay' \\ 'Department of Emergency Medicine, Trakya University School of Medicine, Edirne, Turkey \\ 2Department of Orthopedics and Traumatology, Trakya University School of Medicine, Edirne, Turkey
}

\begin{abstract}
Introduction: Fat embolism syndrome (FES) is a potentially lethal complication of long bone fractures and is commonly seen after femur fractures. The clinical manifestations of FES are as follows: petechiae, pulmonary dysfunction, mental status changes, tachycardia, fever, thrombocytopenia, and anemia. FES can result in multiorgan dysfunction such as that of the brain, skin, and lungs. In this case report, we present a rare case of FES after traumatic fracture of the tibia and fibula.

Case Report: A 32-year-old male patient was admitted to our emergency department $18 \mathrm{~h}$ after a traffic accident. He was previously healthy and had no medical history. At initial examination, a right shoulder fracture and dislocation and left tibia and fibula open fractures were detected. Almost $2 \mathrm{~h}$ after admission, he started to complain of difficulty in breathing. At the same time, petechiae appeared on his chest wall. With these clinical features, FES was diagnosed.

Conclusion: With the presentation of this case report, we aim to improve the awareness and knowledge of Emergency Physicians regarding FES, such that they might keep in mind the diagnosis of FES in patients admitted to emergency departments with a long bone fracture and respiratory impairment.
\end{abstract}

Keywords: Emergency department, fat embolism, trauma

Received: 23.11.2015 Accepted: 28.01.2016 Available Online Date: 16.02.2016

\section{Introduction}

Fat embolism syndrome (FES) is a potentially lethal complication of long bone fractures and is commonly seen after femur fractures (1). However, it is rarely seen after other fractures than those of the femur. It was the first described by Zenker 150 years ago (2). The clinical manifestations of FES are as follows: petechiae, pulmonary dysfunction, mental status changes, tachycardia, fever, thrombocytopenia, and anemia. FES can result in multiorgan dysfunction such as that of the brain, skin, and lungs (3). Most cases are related with multiple trauma and systemic inflammatory response syndrome $(3,4)$; however, a few cases have been reported related to long bone fractures other than the femur $(3,5)$. Major and minor diagnostic criteria of FES were published by Gurd and Wilson (1) (Table 1) that can be useful for physicians.

There also exists a diagnostic tool to help the diagnosis of FES called the "fat embolism index (FEI)". This index was prepared by Schonfeld, and a total score of five or more in the first three days of hospitalization supports the diagnosis of FES (6) (Table 2).

Fat embolism syndrome can also be seen in the situation of pancreatitis. In this case report, we present a rare case of FES after a traumatic fracture of the tibia and fibula.

\section{Case Report}

A 32 year-old-male patient was admitted to our emergency department $18 \mathrm{~h}$ after a traffic accident. He was previously healthy and had no medical history. At initial examination, a right shoulder fracture and dislocation and left tibia and fibula open fractures (Gustilo grade III C) were detected (Figure 1). 
Table 1. Gurd and Wilson's major and minor criteria for fat embolism. The presence of one major feature, four minor features, and fat macroglobulinemia is diagnostic of FES $(1,9)$.

\begin{tabular}{ll} 
Major criteria & Minor criteria \\
\hline Petechial rash & Tachycardia \\
$\begin{array}{l}\text { Respiratory symptoms with } \\
\text { bilateral positive radiographic } \\
\text { changes }\end{array}$ & Pyrexia \\
\hline $\begin{array}{l}\text { Cerabral signs unrelated to } \\
\text { head injury }\end{array}$ & Retinal fat or petechia \\
& Urinary fat globules or oligoanuria \\
& Sudden drop in hemoglobin level \\
& Sudden thrombocytopenia \\
& High erythrocyte sedimentation rate \\
& Fat globules in sputum
\end{tabular}

Table 2. Schonfeld's Fat Embolism Index (FEI) score. A score of five or more points in the first three days of hospitalization is diagnostic of FES (10).

\begin{tabular}{ll} 
Points & \\
Diffuse petechiae & 5 \\
\hline Alveolar infiltrates & 4 \\
Hypoxemia $(<70 \mathrm{~mm} \mathrm{Hg})$ & 3 \\
Confusion & 1 \\
Fever $>38^{\circ} \mathrm{C}$ & 1 \\
Heart rate $>120$ beats $/ \mathrm{min}$ & 1 \\
Respiratory rate $>30 / \mathrm{min}$ & 1
\end{tabular}

Cranial, thoracic, and abdominal computed tomography (CT) imaging were performed, which revealed normal results. The patient's Glasgow Coma Scale Score (GCS) was initially 15. Intravenous fluid replacement and antibiotherapy were started. The vital signs of the patient were as follows: blood pressure, 110/80 mmHg; heart rate, 90 beats/min; respiratory rate, 18 ; and oxygen saturation, $96 \%$ on room air. He had an arterial blood gas $\mathrm{pH}$ of $7.38, \mathrm{pCO}_{2}$ of $40 \mathrm{mmHg}, \mathrm{pO}_{2}$ of $82 \mathrm{mmHg}$, and -9 base deficit initially. Hemoglobin, hematocrit, and platelet levels of the patient were $13.8 \mathrm{gr} / \mathrm{dL}, 40.4 \%$, and 203/ $\mathrm{mm}^{3}$, respectively. Almost $2 \mathrm{~h}$ after admission, he started to complain of difficulty in breathing, and his GCS score deteriorated to 13. At the same time, petechiae appeared on his chest wall (Figure 2).

In this period, a second laboratory analysis was performed and the results showed that his hemoglobin dropped from $13.8 \mathrm{~g} / \mathrm{dL}$ to 10.3 $\mathrm{g} / \mathrm{dL}$, and his platelet count dropped to $98 / \mathrm{mm}^{3}$.

With these clinical features, a diagnosis of FES was diagnosed and intravenous prednisone treatment started with high-flow oxygen therapy. A few hours after the initiation of the therapy, patient symptoms completely resolved. To exclude the diagnosis of pulmonary thromboembolism, a CT-pulmonary angiogram was performed and revealed normal findings. Furthermore, brain CT and MRI revealed

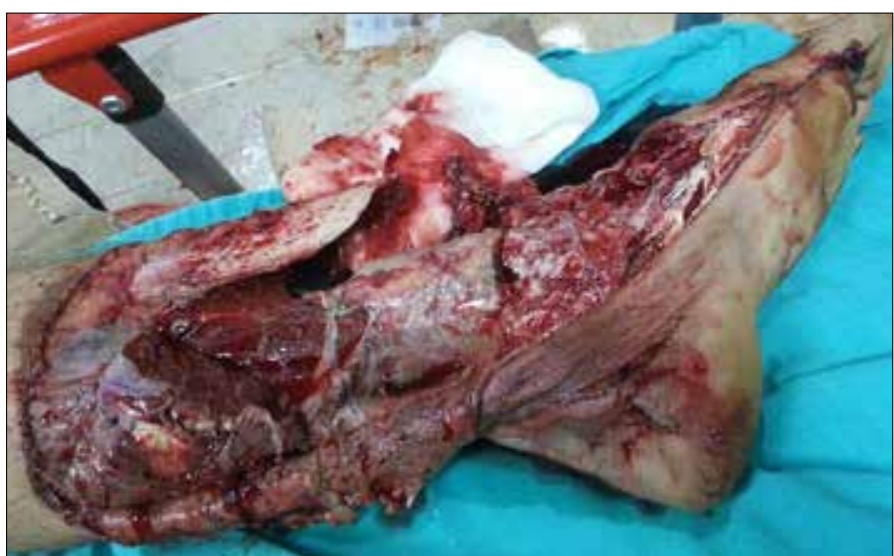

FIGURE 1. Left tibia and fibula open fractures (Gustilo-Anderson grade III C)

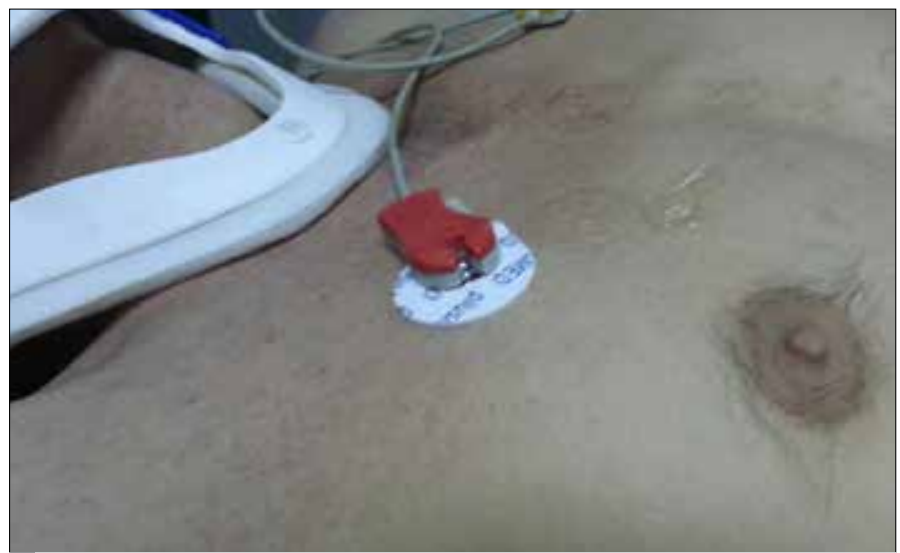

FIGURE 2. Petechiae on the chest wall

normal results. During the follow up period, the neurological status of the patient started to improve. After a complete recovery, the patient was transferred to the orthopedic clinic for operation. We obtained written informed consent from the patient fort he publication.

\section{Discussion}

The present report describes FES that was treated without any sequelae. This syndrome is commonly seen in the second and third decades related to trauma incidence This syndrome is commonly seen in trauma patients who are between 20-30 year old (1). For clinicians, it is important to know the difference between FES and fat embolism because fat embolism is not a life threatening condition and can be seen in almost 90\% of patients with traumatic wound, whereas FES can be mortal if not adequately treated $(1,7)$. In the diagnosis of FES, there are some clinical tools available, such as Gurd and Wilson's major and minor criteria for fat embolism and Schonfeld's FEl score. But these are not gold standard in the diagnosis. Up to now, the diagnosis of FES has remained clinical (8). In clinical evaluation, there is a classical triad of FES that includes hypoxemia, petechiae, and neurological abnormalities (9). However, there are also commonly seen pulmonary findings such as dyspnea, tachypnea, and respiratory failure (4). Neurological abnormalities may be related 
to hypoxemia and fat embolism to the brain vessels (9). The pathophysiological mechanism of FES is still unclear, although there are some theories to explain the mechanism, such as the mechanical theory proposed by Gauss (1). According to this theory, fat particles drop into the circulation after a trauma of long bones and are then transported to the capillary bed of the lungs and cause ventilationperfusion disorder (4). The second theory is the biochemical theory, in which fat tissue in the bone marrow is destructed by tissue lipases, resulting in high concentrations of toxic free fatty acids that occur in the circulation. This damages the endothelial cells of the lungs and causes cytotoxic edema $(2,9)$. Petechia occurs because of the occlusion of dermal capillaries and also the extravasation of the erythrocytes. It is seen in 20\%-50\% of patients and typically resolves in a short period (7). There is no specific treatment of FES, but supportive treatment is acceptable. In clinical practice, corticosteroids are routinely administered; however, there are no sufficient evidences for its effectiveness (True) (9). Using heparin for systemic anticoagulation may accelerate the clearance of lipid drops from the circulation, but it may exacerbate the underlying proinflammatory physiology (10). In this way, the best treatment modality of FES is supportive intensive care unit-level treatment. In our case, the patient dramatically recovered after adequate oxygen and steroid treatment. However, in some cases, patients may need mechanical ventilation and should be observed in an intensive care unit.

\section{Conclusion}

With the presentation of this case report, we aim to improve the knowledge of Emergency Physicians regarding FES, so that they might keep in mind the diagnosis of FES in patients admitted to emergency departments with a long bone fracture and respiratory impairment.

Informed Consent Written informed consent was obtained from patient who participated in this case.
Peer-review: Externally peer-reviewed.

Author Contributions: Concept - M.B.S.; Design - O.S.; Supervision - M.B.S.; Materials - V.M.; Data Collection and/or Processing - M.B.S.; Analysis and/or Interpretation - O.S.; Literature Review M.O.; Writer - O.S.; Critical Review M.B.S.

Conflict of Interest: The authors declared no conflict of interest.

Financial Disclosure: The authors declared that this study has received no financial support.

\section{References}

1. Akoh CC, Schick C, Otero J, Karam M. Fat embolism syndrome after femur fracture fixation: a case report. lowa Orthop J 2014; 34: 55-62.

2. Kwiatt ME, Seamon MJ. Fat embolism syndrome. Int J Crit IIIn Inj Sci 2013; 31: 64-8. [CrossRef]

3. Scuderi CS. The present status of fat embolism. Bibliographic review. Int Surg Digest 1934; 18: 195-215

4. Sara S, Kenyhertz G, Herbert T, Lundeen GA. Fat emboli syndrome in a nondisplaced tibia fracture. J Orthop Trauma 2011; 25: e27-9. [CrossRef]

5. Kallina C, Probe RA: Paradoxical fat embolism after intramedullary rodding. J Orthop Trauma 2001; 15: 442-5. [CrossRef]

6. Schonfeld SA, Ploysongsang Y, DiLisio R, Crissman JD, Miller E, Hammerschmidt DE, et al. Fat embolism prophylaxis with corticosteroid: A prospective study in high-risk patients. Ann Int Med 1983; 99: 438-43. [CrossRef]

7. Gurd, AR. Wilson RI. The Fat Embolism Syndrome. J Bone Joint Surg Br 1974; 56B: 408-16.

8. Georgopoulos D, Bouros D: Fat embolism syndrome: clinical examination is still the preferable diagnostic method. Chest 2003; 123: 982-3. [CrossRef]

9. Kosova E, Bergmark B, Piazza G. Fat Embolism Syndrome. Circulation. 2015; 131: 317-20. [CrossRef]

10. Eriksson EA, Pellegrini DC, VanderkolkWE, Minshall CT, Fakhry SM, Cohle SD. Incidence of pulmonary fat embolism at autopsy: an undiagnosed epidemic. J Trauma 2011; 71: 312-5. [CrossRef] 